\title{
Independent state-funded schools: some reflections on recent developments
}

\section{Christopher Chapman \& Maija Salokangas}

To cite this article: Christopher Chapman \& Maija Salokangas (2012) Independent state-funded schools: some reflections on recent developments, School Leadership \& Management, 32:5, 473-486, DOI: 10.1080/13632434.2012.731329

To link to this article: https://doi.org/10.1080/13632434.2012.731329

册 Published online: 30 Oct 2012.

Submit your article to this journal $₫$

山ll Article views: 944

Q View related articles ๘

4 Citing articles: 20 View citing articles 진 


\title{
Independent state-funded schools: some reflections on recent developments
}

\author{
Christopher Chapman* and Maija Salokangas \\ School of Education, University of Manchester, Manchester, UK
}

\begin{abstract}
Educational systems around the world are experimenting with new forms of schooling. One example is the emergence of independent state-funded schools (ISFSs). In the USA these have taken the form of Charter Schools. In Sweden chains of Free Schools have been established and in England Academies and most recently Free Schools have been placed at the centre of government reforms. This article offers clarity of definition relating to ISFSs and chains of ISFSs and charts some of the features of these recent developments, highlighting a shift in emphasis of improvement efforts from individual schools to collaborative chains and federations. In conclusion this article argues that ISFSs are supporting a shift from Individualised school improvement to a collaborative form of Federal improvement, but within the current arrangements they are unlikely to be able to support broader systemic improvement efforts unless attention is paid to both structural and cultural change.
\end{abstract}

Keywords: academies; charter schools; free schools; governance; school choice

\section{Introduction}

Despite huge investment in resources the link between poverty and low educational achievement remains as steadfast as ever. Recent responses designed to tackle this situation have involved various governments experimenting with policies designed to target raising educational standards in schools serving the poorest and often most challenging communities, usually in urban settings. One approach adopted across a number of systems has been to increase the role of the market in education, promoting the involvement of the private sector. Increased competition and deregulation has led to significant changes to organisational and governance arrangements. These developments have also supported the emergence of schools funded through public taxation mechanisms while being awarded significant freedoms from traditional district or local government control. These independent state-funded schools (ISFSs) have gained prominence in a number of education systems including England, the USA, Sweden and Australia (Lundahl 2007; Ball 1998; Hudson and Lidström 2002). However, there are examples of ISFSs operating in contexts as diverse as Chile, Colombia and New Zealand (Bettinger 2009; Bellei 2009).

In most contexts ISFSs tend to establish themselves as part of a wider neo-liberal political agenda which can be viewed as part of governance transition (OECD 1995). Features of governance transition include creating alternatives to public provision,

*Corresponding author. Email: chris.chapman@manchester.ac.uk 
developing competitive environments through the usage of user fees or vouchers, decentralising management in order to increase operative autonomy and flexibility as well as focusing on results, efficiency, effectiveness and quality.

However, despite the significant policy interest there remains a paucity of research evidence relating to the impact of ISFSs and the structures and processes related to their sustainable improvement. Put simply, the jury is out as to whether these schools provide a more effective mechanism for raising standards in our most challenging settings than their predecessors.

This article sets out to achieve three aims. First, it addresses the lack of clarity regarding definitions and understandings about ISFSs, by defining the key terms. Second, the paper reflects on the shift from individual or loosely coupled ISFSs to groups or chains, and hence from individualised to federal improvement efforts. Third, and in conclusion, the paper concludes by speculating on the potential of federal improvement to support systemic improvement efforts.

\section{Defining the terrain: understanding ISFSs, groups and chains}

\subsection{What are ISFSs?}

ISFSs are publicly funded schools. These schools enjoy higher degrees of autonomy compared to traditional publicly funded and managed schools. This autonomy varies depending on country and type of ISFSs, but in most cases encompasses freedoms from local government control, freedom over geographic enrollment restrictions, curriculum and teacher union restrictions (LaRocque 2008). The main philosophical argument for these freedoms is based on the assumption that these conditions promote innovation and raise educational standards. Innovation in ISFSs has led to varying degrees of specialisation in curricula or ideological function (Hudson and Lindström 2002). Involvement of the private sector combined with freedom from local government control has led to some of these schools developing stronger relationships with business than many of their traditional state-funded counterparts.

In England ISFSs can be traced back to the 1988 Education Reform Act and the launch of City Technology Colleges. However, the Academies programme, modelled on Charter Schools in the USA, was first announced in England in 2000, by Education Secretary David Blunkett, as a replacement for the 'Fresh Start' policy of reconstituting failing schools, another policy to have travelled across the Atlantic. These early academies were designed to transform education in the most challenging urban settings. They were provided with significant resources from the state and were supported by a 'sponsor' who until 2007 was required to invest $£ 2$ million in the school. This injection of resource and outside interest was an energetic attempt to tackle persistent low attainment and aspiration and ultimately to break the cycle between low educational outcomes and poverty. The change in sponsorship arrangements in 2007 signalled a change in policy direction. As New Labour attempted to scale up their project it became more difficult to find sponsors who fitted the criteria for sponsorship or had significant resource to invest. Most recently, we have seen the current coalition government commit to an 'academised' system whereby all schools enjoy the freedoms of academy status. The first phase of this project saw the most successful schools within the system being able to convert into academies and the introduction of primary academy schools. Sponsors have become 
increasingly diverse and schools themselves have been encouraged to lead other schools in an attempt to create the 'self-improving school system' (Hargreaves 2010).

Charter Schools are non-selective, state schools which have more freedom than traditional state schools in the USA, the charter being the agreement that describes the schools' mission, vision and methods. Charters usually have between three and five years to establish themselves as effective educational institutions otherwise their charter will not be renewed. They are accountable to parents, taxpayers and the state and can be created and operated by charities, teachers or parental groups and even companies. Since 2002, 40 states have been granted permission to open Charter Schools, and there are currently over 350,000 parents on Charter School waiting lists (NSN 2012a).

Swedish Free Schools (Friskolor) are also independent, non-fee paying and nonselective but vary widely in their approach and in the type of education they offer (e.g. from 'child centred' to more traditional schooling). They also receive $100 \%$ of the per-capita funding of state schools. Established in 1992, over $20 \%$ of all Swedish Schools are now Friskolor, though these are often smaller than state schools with an average of around 130 pupils. They tend to be run by parents and community groups (mainly in rural areas) and offer an alternative approach to teaching (such as Montessori). Teachers are attracted by the freedom and flexibility on offer (NSN 2012b). One of the higher-profile Swedish Free School chains is Kunskapsskolan (the knowledge school), which runs 33 schools and advocates the methods of pedagogy which place more learning responsibility with the pupils via radical steps such as the removal of classrooms and allowing pupils to choose when, where and what to participate in, although they too are obliged to follow the national curriculum. Pupils work at their chosen level, selected from 35 steps through negotiation with teachers. Kunskapsskolan are sponsors of three new academies in England (two in London and one in Suffolk).

These 'free floating' schools, independent of local government control, have their own sponsoring strategic managing executive (SME) responsible for overall governance and strategic direction. For example, in England, SMEs have taken over some of the functions provided by local authorities (school districts) and are responsible for various aspects including standards and quality assurance, hiring and firing principals and other key staff, and legal and financial matters. Responsibility for these functions is made possible by 'top slicing' school budgets (5\% in the case of one SME running a group of academies). In one sense, this has recreated a new form of (local) educational authority that provides support and administrative functions to schools. SMEs act as commissioner of services for professional development and school improvement. Many have lists of approved providers, including private consultants, academics and ex-government quangos such as the Specialist Schools and Academies Trust. In some cases SMEs have their own 'delivery arm' providing support for school improvement 'in house'. In practice, the second producer-consumer model means that individual schools have little choice about the nature or extent of the services they receive. In effect this reproduces traditional local authority arrangements. SMEs also exhibit considerable diversity in:

- underpinning philosophy and aims concerning education;

- vision and aims for children and society; 
- methods and purposes needed to achieve their aims;

- operational structures and processes put in place within their organisations;

- size.

Given the diversity outlined above it is not surprising that those responsible for the executive management of ISFSs come from a wide range of backgrounds, with varied experiences. These range from faith interests, philanthropic and commercial backgrounds to those who have a track record in education and government. The commitment and diversity of the executive management often lead to the schools developing powerful cultural identities and a strong brand.

This complex set of arrangements leads us to define ISFSs as schools that are funded by the state but operate outside of local government arrangements. In one sense they are 'free', in another they are not because they tend to be tied in to central government accountability structures through their SME and government departments or quangos.

The replication of policies across diverse education systems indicates the rise of an ISFS movement. This movement is underpinned by a range of core beliefs:

(1) Schools rather than a government know best how to deploy and invest resources.

(2) Autonomy from local government structures leads to a rise in educational standards.

(3) Increasing the range of educational providers leads to improved educational standards.

Put simply, the rise of this movement is underpinned by a set of neo-liberal beliefs in which the market provides the stimulus for educational change and ultimately, improved educational standards (Gunter 2011).

\subsection{From one to many: the rise of groups and chains of ISFSs}

The rise of ISFSs has become somewhat of a cult. The international evidence for pursuing this agenda remains at best mixed. However, think tank reports promoting neo-liberal ideas have become powerful and persuasive tools for policy makers to implement their political agendas. This is particularly evident in England where there is a strong political commitment to developing federations and chains of academies.

For example, The Policy Exchange (2009) publication A Guide to School Choice Reforms focuses on the experiences of three systems: Academies in England, Free Schools in Sweden and Charter Schools in the USA, to argue that the pursuit of systems involving ISFSs naturally promotes the development of federations or chains of schools. The Policy Exchange also claims that the intention of reformers in each of the systems under scrutiny was not to develop these arrangements, rather federations and chains are a natural consequence of promoting ISFSs. Furthermore, the absence of a planned shift to federations and chains means that these systems also have elements acting as barriers to their emergence and have tended to limit the extent of their existence and, 'Allowing commercial companies to set up ISFS significantly 
boosts the potential for federation' (57). In contrast to the assured nature of these claims the Policy Exchange also notes:

In the UK and Sweden there have been no statistical comparisons of performance between federations and one-offs. Nevertheless the initial data on academies suggests that multi-academy groups are outperforming sponsors with one or two schools. (Policy Exchange 2009, 56)

Since this publication there have been two studies in England (Chapman et al. 2009; Chapman, Muijs, and MacAllister 2011) which identified significant impact of 'performance federations' and 'academy chains' on student outcomes compared to a matched sample of their non-federated counterparts. The most recent study also associated executive leadership, where a principal takes responsibility for the leadership of two or more schools, with higher levels of impact than traditional leadership structures. However, the relationship between educational change and improvement and chains and academies remains a seriously under-researched area.

We know very little about the differential impact of chains, the impact of chain size on student outcomes or the relationship between governance arrangements, community and impact, although there is some early evidence suggesting differential impact between highly centralised and decentralised chains (Muijs, Chapman, and Reynolds 2012). Clearly, as with ISFSs, chains and federations are areas requiring urgent further investigation to establish the efficiency and effectiveness of these new models of schooling.

While the empirical evidence to support these claims is at best limited, the ideas and arguments made by the Policy Exchange and other similar pamphlets have been influential and can be seen in the UK government's agenda for school reform in England (Department for Education [DfE] 2010).

The Government's White Paper (DfE 2010) makes bold claims and confirms policy commitments to readjusting school autonomy and redefining notions of accountability by encouraging the establishment of Federations, groups and chains of outstanding schools, academies and free schools:

\begin{abstract}
Schools working together leads to better results. Some sponsors already oversee several Academies in a geographical group, or chains of Academies across the country, and already seven organisations sponsor six or more Academies. These chains can support schools to improve more rapidly. Along with our best schools, we will encourage strong and experienced sponsors to play a leadership role in driving the improvement of the whole school system, including through leading more formal federations and chains. (DfE 2010, 60)
\end{abstract}

Handing over control for improvement to our best ISFSs and SMEs and promoting collaboration across school boundaries are all key features of the next phase of educational reform and will require new forms of leadership. Glatter (2006) has called for a reorientation of leadership and organisation in education and there has been increasing interest in the relationship between school leadership and outcomes, leading to strong claims about successful school leadership (Leithwood, Harris, and Hopkins 2008). The leadership discourse that emerged in the 2000s under New Labour and the National College for School Leadership remains central to current policy and is likely to require ever more complex approaches, combining 
entrepreneurial, collaborative and instructional elements in order to move between organisational boundaries and emerging lateral and vertical structural arrangements within the system. This leadership may play an important role in the emergence of what Hargreaves has described as a self-improving school system where:

...more control and responsibility passes to the local level in a spirit of mutual aid between school leaders and their colleagues, who are morally committed to imaginative and sustainable ways of achieving more ambitious and better outcomes. (Hargreaves 2010, 23)

In an attempt to better understand how these reforms play out in practice it is helpful to draw on Mary Douglas's Grid Group Cultural Theory and latterly Hood's (1998) application of this theory within public services. Hood argues that egalitarian cultures assume low grid characteristics with few central rules, low levels of regulation and ascribed behaviours, combined with high group characteristics including strong collaborative relationships between group members within welldefined boundaries. It could be argued that successful federations and chains would be likely to require organisational and regulative flexibility and strong collaborative relationships, and, therefore, one might assume an egalitarianism culture would be an ideal context.

Hood (1998) has argued that public service provision within these egalitarian environments comes in the form of 'mutual' organisations. Such organisations are characterised by mutual relationships, which transcend traditional conceptions of service provider and user. Put simply, the concept of a service provider becomes redundant as the users collectively deliver services themselves. This fits with the notion of the self-improving school system where federations and chains of schools take responsibility not only for the teaching and learning of students but also for initial teacher education, continuing professional development and other forms of services.

Therefore, it would seem egalitarian cultures might be a prerequisite for a selfimproving schools system led by ISFSs. But does such a culture exist in contexts pursuing ISFS self-improving systems? England and the USA are dominated by low grid and low group characteristics which lead to individualised cultures where the market dominates and users are portrayed as customers contracted within a competitive market. This situation seems to be missing the elements required to nurture mutual organisations in an egalitarian culture that would be likely to support a self-improving school system.

Despite these cultural tensions policy development has remained steadfast, focusing on changing structural arrangements to promote ISFSs. As the ISFS movement has gathered momentum groups of schools co-ordinated by one provider have become more common. For example, The 'KIPP' Charter schools in the USA have grown to become a powerful group, influencing policy in the USA and beyond. In Sweden the Baggiums Praktiska Gymnasier and Kunkapskola groups have also been serious players, influencing policy. In England we have also seen the emergence of a number of powerful SMEs including Ark, Harris, EAct and United Learning (formerly United Learning Trust [ULT]).

The groups of schools run by these organisations are subjected to a range of interchangeable labels. Federations, chains, network, group, family and even 
franchise have been used to describe their arrangements. This is further complicated when attempting to traverse different systems, languages and cultures. For example, in the US Charter Management Organisations (CMOs) are used to describe SMEs. In England there are 'local governing bodies' and 'trust boards' led by Academy SMEs. These terms are also often used interchangeably and can mean different things in different settings. Furthermore, these terms are often wrapped up in the quagmire of political and policy makers' language.

This said, in England, chain, federation and group are most commonly used to describe groups of ISFSs (ARK 2011; Glatter 2011; Harris Federation 2011; Policy Exchange 2009; ULT 2011). In one of the rare pieces of research looking at specifically several schools under the same SME operating in England, Hill (2010) finds the term 'chain' most suitable. He argues that in addition to an effective and clear corporate model of governance and the centralised resources and systems these groups have, a strong vision and values are also shared within these groups. Furthermore, within these groups, strong teaching and learning models tend to be put in place and monitored by quality assurance mechanisms set by the central governance (Hill 2010).

We draw on these arguments to describe a chain of schools as a group of schools working together under a common brand and governance framework. This structure is controlled by an SME that delegates some decision-making to the local level so school principals and local governance arrangements can adapt central 'chain policies' to their school and community context. The extent to which local variations in chain policy occur in practice varies from chain to chain and is determined by the SME's underlying philosophy, vision, values and modus operandi.

The number of schools under one SME's control varies. There are still examples of stand-alone ISFSs (and with the development of the Free Schools in England their number may increase, at least in the short term), but most now operate as chains. The number and spread of existing chains of Academies in England have grown steadily, with many SMEs planning on extending further (Glatter 2011). According to Hill (2010), by the spring of 2008 there were already over 40 chains run by SMEs in England. In September 2011 United Learning Trust (ULT) had 24 schools, the largest chain in England. However, EAct's Director General, Sir Bruce Liddington, outlined the plans of creating a 'super chain', expanding EAct from 11 to 250 schools within a five-year period (TES 2011). By September 2012 there were 2309 academies open in England. These include stand-alone academies, primary and secondary academies and those operating as part of a chain of three or more schools.

England is not the only country in which the chains play a significant part in the ISFS provision. In the USA the National Resource Center on Charter School Finance and Governance (2009) reported two Charter Management Organisations running over 30 schools. The number and reach of ISFS chains have also grown exponentially in Sweden, especially on the upper secondary level on which chains of Free Schools dominate the education provision (Arreman and Holm 2011). The largest Free School chain during the academic year 2009-2010 was Baggiums Praktiska Gymnasier which ran 52 schools; Vittra ran 34 schools and John Bauer gymnasiet ran 29 schools (Baggium 2011; Bauer 2011; Vittra 2011). 


\section{Federations and chains of ISFSs: from individualised to federal improvement?}

Our monitoring of developments and programme of research in England (e.g. Chapman et al. 2008, 2009; Chapman, Muijs, and MacAllister 2011; Salonkangas 2011; Mongon and Chapman 2012) combined with our collaborative work with colleagues in the USA and to a lesser degree in Sweden lead us to reflect that the focus of improvement efforts in ISFSs is shifting from the individual to federal.

It seems, the type of improvements that tends to be found in stand-alone or loosely coupled ISFSs, particularly in England and the USA, focuses on Individualistic School Improvement efforts. Individualistic School Improvement in ISFSs tends to be underpinned by six core elements:

(1) Strong leadership, expectations and cultural norms - Strong leadership providing a clear vision with a strong desire to make a difference in the lives of children from disadvantaged backgrounds. The belief that all can succeed and achieve their best is common; this is communicated and constantly reinforced. One principal of a case study Academy in our research believed that the Academy is the most stable element of many of their students' lives and their best chance for breaking a cycle of deprivation that has seen three generations of underachievement, underemployment, high teenage pregnancy and crime rates. Our broader experience suggests that this is likely to be a common view.

(2) Focus on teaching and learning - Teaching and learning is underpinned by a strong model of what effective teaching looks like in a given context. There are often clear guidelines in place and lessons are highly structured with many routines. These range from rather formulaic starter activities where students work alone on a clearly defined introductory task to common plenary standardised sessions across the curriculum.

Combined with:

(3) Strong management structures - These structures serve to provide clear lines of communication. This supports organisational efficiency by promoting consistent practice and avoiding duplication of effort. The clear management systems also support simple accountability structures. This can be seen in the way restorative justice is applied to students in some Charter Schools and through staff performance management in Academies.

(4) Focus on raising student and staff aspirations and expectations - These schools promote a 'can do' culture. Staff tend to mirror the high expectations and aspirations of the senior leadership. Any sign of deviation is swiftly and robustly challenged. ISFSs are learning focused organisations, staff are expected to engage in professional development and students are expected to continue their education beyond compulsory schooling through 'graduation' or progression into Further Education (FE). Symbols are often used to reinforce aspirations and expectations. For example naming classes after the teachers' colleges and having graduation photographs and college banners on the wall are commonplace in Charter Schools.

(5) Focus on literacy and numeracy - These skills tend to dominate the curriculum. The rationale being that literacy and numeracy are the cornerstones 
of learning and without basic competency in these areas students cannot access the broader curriculum. In some cases this has the effect of narrowing the curriculum, so students' experiences of schooling become limited to a few core subjects, in other settings schools have introduced other methods such as a Charter School that had introduced critical thinking sessions and an Academy that uses drama to develop literacy and numeracy skills.

(6) Use of data to identify underperformance and set challenging targets - These schools are awash with data. They invest considerable time and energy compiling data to enable decision-making. This tends to be done at school, subject and individual levels. Therefore, this is capable of identifying the areas of staff and student underperformance and setting individual targets to support improvements in teaching and learning. In one Academy there is a whole room and team dedicated to the 'use of data'. Every student is on a traffic light system of green, amber and red, with amber and red triggering an immediate intervention. Similarly, every head of department is aware of their subject area target and whether they are on track to hit the target or not. In turn, these are monitored by senior leadership.

Put simply, the features of what we see in this individualised approach to improvement in ISFSs are not new; they are what Ainscow and colleagues at the University of Cambridge termed cultural 'hothouses' almost 20 years ago (Ainscow et al. 1994) and reflect much of what has been written about school improvement in challenging contexts in the interim (see Stoll and Fink 1996; Harris and Chapman 2002; Muijs et al. 2004; Chapman 2006). The approaches also echo some of the characteristics of 'third wave school improvement' (Hopkins and Reynolds 2001). Given the attention school improvement has received over the past decades this lack of progress is rather disappointing. It would seem our supposedly most innovative schools, serving our most challenging communities appear to be applying the same (rather blunt) levers for improvement that we have been relying on for over a decade. Furthermore, it is becoming clearer the returns from this approach have been somewhat limited and have failed to address the key issues of inequity and variation in outcomes between different groups of learners within the system. Put simply, the attainment gap between more and less affluent students remains as strong as ever.

The growth of the ISFS movement and the emergence of ISFS chains have led to new inter-dependent structural arrangements across groups of schools coordinated by CMOs in the USA and SMEs in England. The organising bodies tend to be entrepreneurial in nature and are often keen to brand and replicate a model of education. This emerging context has also presented new opportunities for structured school-to-school collaboration that in the past have been limited by the problematic nature of collaborating in a quasi-market. These arrangements have facilitated a shift of focus from Individualised School Improvement towards Federal Improvement effort whereby the improvement of all schools across the chain is the ultimate goal. The key characteristics of Federal Improvement efforts are:

(1) Centralised co-ordination of some functions by a central body - These functions serve to provide administrative support, strategic direction, challenge and support to schools across the chain. Within Academy chains 
SMEs tend to make most, if not all of the strategic decisions concerning the development of the chain and individual schools. This has resulted in two-tier governance structures whereby the 'local' governing body often has very little decision-making power or influence over policy or strategy. This erosion of power has important implications for local democracy and raises important questions about community involvement and ownership of their school.

(2) Benefit from administrative economies of scale - Some of the centralised functions of the CMOs and SMEs lead to economies of scale of administrative functions. For example an individual school might not be able to hire a dedicated administrative officer to deal with legal issues, marketing or personnel; however, this may be possible across a chain. This has the effect of taking these responsibilities (which have become part of many principals' remit in England) away from the principals, freeing them up to focus on improving educational standards. So the benefits are two-fold. First, increased administrative capacity and second, increased capacity to focus on raising educational standards. There is an opportunity cost of course: what would the Academy choose to do with the part of its budget used to resource the SME or what power does the individual school have to quality assure the functions provided by the SME?

(3) Development of chain-wide approaches to CPD - This tends to be either sourced externally or coordinated internally within the CMO or SME. In one Academy chain it involved the hiring of external consultants to work on issues such as 'within-school variation', organising conferences and workshops led by external trainers and drawing on expertise from different schools and faculties within the chain to share approaches to leadership, management and pedagogical practice through workshops and seminars. However, there is significance in how co-ordinated or ad hoc these arrangements are. While a number of chains have developed strong pedagogical methodologies and accompanying CPD programmes, others have chosen to give individual schools the autonomy to develop their own contextualised approaches with little structured exchange of knowledge or practice across the chain.

(4) Supports succession planning and career management - Federal improvement provides greater opportunities for staff to take on more senior positions of responsibility within their own school or another school within the chain. Where there is a strategic overview this can serve as an effective lever for professional development and can support succession planning and career development of individuals across the chain. However, the movement of staff around the chain can also be used as a reactive model of crisis management. In some cases this has led to demotivation of staff, and tensions between host staff and those entering on secondment from another academy within the chain. In some cases this has further destabilised a vulnerable school.

(5) In-house tailored support for 'struggling' and lower-performing schools, departments and individuals across the chain - Approaches tend to focus on baselining expectations and developing standardised approaches to teaching and learning and quality assurance in an attempt to develop and conform to the in house' model of schooling. This point is linked to the previous two as this support and capacity building involves staff within the chain taking on system leader roles, providing CPD and opportunities for career development for those providing the support, and raises the same issues as those outlined above. 
(6) Commitment to promoting the 'brand' - Chains of ISFSs create strong chain identities. Chains of ISFSs can be followed on Twitter and Facebook (e.g. KIPP), and the inter-chain competition can be strong. Academy chains are very aware of other chains' performance and have found themselves competing for schools wanting to convert to Academy status under the English government's programme of ISFS expansion. This form of competition can serve to sharpen the focus of academy chains. However, it may also act as a barrier to inter-chain collaboration and lead to a further narrowing of the curriculum and concentration on basic test scores.

In summary, ISFSs tend to be driven by a clear vision and mission. Some are driven by prescriptive models of Federal improvement based on a philosophy of replication and fidelity of implementation with little regard for context specificity. For example, one Academy chain works on the basis of an 80:20 ratio, believing $80 \%$ of effective schooling is generalisable, leaving $20 \%$ specific to the particular context. While at the other extreme there is another Academy chain where central direction and prescription are almost non-existent, leaving principals to develop their own approaches. The philosophy of this chain is 'it does not matter how you get there, do what works in your context'. The principals are held to account through a set of accountability systems involving key performance indicators (KPIs). Failure to meet these KPIs results in intervention from the SME. While one can identify a number of key characteristics of federal improvement, one of the most striking feature of ISFSs is the extent to which detailed policies and practice vary between chains, and it would seem that this is closely linked to the CEO's vision and philosophy for the chain rather than those involved with the day-to-day leadership and management of schools within the chain.

\section{Reflecting on individualised and Federal improvement - a precursor to systemic improvement?}

As this new order plays out in the field, our observations suggest that practice is evolving at such a rate there is a danger of policy lagging behind. Furthermore, as the system drifts towards Federal improvement, there are some broader and significant changes. First, individualised improvement tends to be underpinned by high levels of autonomy combined with sharp accountability mechanisms. Most decisions are made at the school level while Federal improvement involves some loss of autonomy but accountability remains high. Most key decisions are made at federal level. Second, individualised improvement is underpinned by a deep understanding of individual school context with opportunities tailored to individual needs and matched to school context and capacity for change while Federal improvement involves the development of standardised chain-wide approaches, leading to some tension between school and federal perspectives. Third, individualised improvement is more vulnerable to changes in the external environment - e.g. political decisions, demographics, while Federal improvement uses its size and economies of scale less as a buffer from the external environment. Fourth, individualised improvement is often fragile (even when sustained), reliant on personnel in key leadership positions and other internal factors, e.g. teacher retention, while in Federal improvement successes tend to be less fragile but it can be catastrophic if the whole chain is viewed as failing - therefore the 
stakes can be even higher. Fifth, individualised improvement is underpinned by little or no commitment to children attending other schools in the locality. Federal improvement generates commitment to a brand that also limits the potential for genuine collaboration with other local schools. Thus, Federal improvement does not promote commitment to children attending other schools outside the chain.

Therefore, while there are some benefits in this shift of improvements' focus, the developments provide a necessary but insufficient ingredient for systemic improvement. Put simply, the potential for systemic improvement through a Federal approach to improvement would appear limited.

\subsection{Commentary: Federal improvement a precursor to systemic improvement?}

The shift from individualised to Federal improvement would seem a welcome development. However, in itself it is unlikely to be enough to generate the systemic improvements and the self-improving school system that many politicians and policy makers crave for. Furthermore, it is too early to assess the impact of many of these new developments or any unintended outcomes on the wider system. However, the arguments presented in this paper attempt to offer some insights and reflections about how we might move forward.

We suggest if there is to be a further shift towards systemic improvement it requires the resolution of a number of key tensions inherent in both individualised and Federal improvement efforts. Such tensions might be resolved through creating a set of facilitative conditions to promote improvement. The first condition for improvement is an appropriate blend of school improvement approaches within chains to support appropriate levels of consistency/fidelity of implementation without stifling innovation. These are likely to combine a complex mix of mechanistic and organic approaches tailored to specific contexts. This is likely to optimise organisational and federal improvement. The second facilitative condition required is inter-dependence for capacity building across chains and the wider system. This will support the generation of system leaders that think beyond their own brand and is likely to move us closer to the concept of systemic improvement. However, under the current arrangements this represents a major challenge. The final condition involves creating joint responsibility for all children in a locality rather than only those on roll in one school/chain. This will involve developing accountability mechanisms that promote shared responsibility for all children irrespective of the school they attend or which chain it is located within. This is also a major challenge under the current arrangements.

Within the current context, the first of these conditions would not appear insurmountable; however, creating the second and third conditions presents significant challenges and will require a fundamental redesign of how the system is arranged and a re-culturing of how our school leaders think about their role as educators.

Put simply, policy makers' determination to achieve their aims through structural change without attending to cultural issues is unlikely to bring about a systemic change underpinned by a self-improving school system. Returning to Hood's (1998) application of Grid Group Theory, it would seem policy makers' and educational leaders' effort should also be focusing on creating egalitarian cultures to support the development of mutualistic organisations rather than relying on individualised 
cultures served by market-orientated organisations. It would seem that unless this complex mix of structural and cultural change can be achieved, ISFSs will not realise their potential as a catalyst for systemic improvement, and the vision for a selfimproving school system will remain an aspiration rather than becoming a reality.

\section{Notes on contributors}

Christopher Chapman is professor of education at the University of Manchester.

Maija Salokangas is a doctoral researcher at the University of Manchester.

\section{References}

Ainscow, M., D. Hopkins, G. Southworth, and M. West. 1994. Creating the conditions for school improvement: A handbook of staff development activities. London: Fulton.

ARK. 2011. ARK Schools: Building better schools. http://www.arkschools.org/ (accessed February 29, 2011).

Arreman, I., and A.-S. Holm. 2011. Privatisation of public education? The emergence of independent upper secondary schools in Sweden. Journal of Education Policy 26, no. 2: 225-43.

Baggium. 2011. Om Baggium. http://www.baggium.se/om-baggium.aspx (accessed April 20, 2011).

Ball, S. 1998. Big policies/small world: An introduction to international perspectives in education policy. Comparative Education 34, no. 2: 119-30.

Bauer, J. 2011. Chain website. http://www.johnbauer.nu/hitta-till-oss_1 (accessed April 20, 2011).

Bellei, C. 2009. The public-private controversy in Chile. In School choice international: Exploring public-private partnerships, ed. R. Chakrabarti and P. Peterson, 165-92. Cambridge, MA: The MIT Press.

Bettinger, E. 2009. Voucher schools in Colombia. In School choice international: exploring public-private partnerships, ed. R. Chakrabarti and P. Peterson, 143-64. Cambridge, MA: The MIT Press.

Chapman, C. 2006. Improving schools through external intervention. London: Continuum.

Chapman, C., M. Ainscow, J. Bragg, H. Gunter, J. Hull, D. Mongon, D. Muijs, and M. West. 2008. Emerging patterns of school leadership: Current practice and future directions. Nottingham: National College.

Chapman, C., D. Muijs, and J. MacAllister. 2011. A study of the impact of school federation on student outcomes. Nottingham: NCSL.

Chapman, C., D. Muijs, P. Sammons, and A. Collins. 2009. A study of the impact of federations on student outcomes. Nottingham: National College.

Department for Education (DfE). 2010. The importance of teaching: The schools White Paper. London: TSO.

Glatter, R. 2006. Leadership and organisation in education: Time for a reorientation? School Leadership \& Management 26, no. 1: 69-83.

Glatter, R. 2011. Joining up the dots: Academies and system coherence. In The state and education policy: The academies programme, ed. H. Gunter, 159-70. London: Continuum.

Gunter, H., ed. 2011. The state and education policy: The academies programme. London: Continuum.

Hargreaves, D. 2010. Creating a self-improving school system. Nottingham: National College. Harris, A., and C. Chapman. 2002. Effective leadership in schools facing challenging circumstances. Nottingham: NCSL.

Harris Federation. 2011. Chain website. http://www.harrisfederation.org.uk/ (accessed May 5, 2011).

Hill, R. 2010. Chain reactions: A think piece on the development of chains of schools in the English school system. Nottingham: National College. 
Hood, C. 1998. The art of the state, culture rhetoric and public management. Oxford: Clarendon Press.

Hopkins, D., and D. Reynolds. 2001. The past, present and future of school improvement: Towards the third age. British Journal of Educational Research 27, no. 4: 459-76.

Hudson, C., and A. Lidström. 2002. National school policy changes in Britain and Sweden. In Local education policies: Comparing Sweden and Britain, ed. C. Hudson and A. Lidström, 27-53. Houndmills, UK: Palgrave.

LaRocque, N. 2008. The practice of public-private partnerships. In School choice international: Exploring public-private partnerships, ed. R. Chakrabarti and P. Peterson, 71-87. Cambridge, MA: The MIT Press.

Leithwood, L., A. Harris, and D. Hopkins. 2008. Seven strong claims about successful school leadership. School Leadership \& Management 28, no. 1: 27-42.

Lundahl, L. 2007. Swedish, European, global: The transformation of the Swedish welfare state. In The RoutledgeFalmer reader in education policy and politics, ed. B. Lingard and J. Ozga, 117-30. Abingdon: Routledge.

Mongon, D., and C. Chapman. 2012. High leverage leadership: Improving outcomes in educational settings. London: Routledge.

Muijs, D., C. Chapman, and D. Reynolds. 2012. Towards franchising in education: An empirical investigation of chains of academies in England. Paper presented at the 25th International Congress of School Improvement and School Effectiveness, January 5-8, in Malmo, Sweden.

Muijs, D., A. Harris, C. Chapman, L. Stoll, and J. Russ. 2004. Improving schools in socially disadvantaged areas: A review of the research evidence. School Effectiveness and School Improvement 15 , no. 2: 149-75.

National Resource Center on Charter School Finance and Governance. 2009. Mapping the landscape of Charter Management Organizations: Issues to consider in supporting replication. Los Angeles, CA: NRC.

NSN (New Schools Network). 2012a. Charter schools in America. http://newschoolsnetwork. org/free-schools/international-examples/charter-schools-america (accessed July 12, 2012).

NSN (New Schools Network). 2012b. International examples. http://newschoolsnetwork.org/ free-schools/international-examples (accessed July 14, 2012).

OECD (Organisation for Economic Co-operation and Development). 1995. Governance in transition: Public management reforms in OECD countries. Paris: OECD.

Policy Exchange. 2009. A guide to school choice reforms. London: Policy Exchange.

Salonkangas, M. 2011. Establishing oneself as researcher in school setting: Reflections on the process through a partnership evaluation. Paper presented to British Educational Research Association, September 7, in London.

Stoll, L., and D. Fink. 1996. Changing our schools. Buckingham: Open University Press.

TES. 2011. Academy sponsor in talks over 'super-chain', March 18. http://www.tes.co.uk/ article.aspx? storycode $=6073399$ (accessed September 10, 2011).

ULT (United Learning). 2011. About us. http://www.ucst.org.uk/about-us/view/41 (accessed March 8, 2011).

Vittra. 2011. Välkommen till Vittra [Welcome to Vittra]. http://www.vittra.se (accessed April 20, 2011). 